\title{
ELECTRODYNAMIC CONTROL OF STRAW CO-FIRING WITH PROPANE
}

\author{
Inesa Barmina, Antons Kolmickovs, Raimonds Valdmanis, Sergejs Vostrikovs \\ Institute of Physics, University of Latvia, Latvia \\ barmina@sal.lv,kolmic@lu.lv,rww@inbox.lv,sv.da@inbox.lv
}

\begin{abstract}
The recent research focuses on the experimental study of the electric field effects on the combustion dynamics during co-firing of straw pellets and propane with the aim to provide control of the thermal decomposition of straw and combustion conditions of combustible volatiles to ensure wider use of straw as fuel for energy production. The experimental studies were carried out using a pilot setup TRL-4. This pilot setup is composed of a gasifier, combustor and a propane burner for co-firing of straw. The electric field was applied to the flame base using the axially inserted electrode with positive bias voltage relative to the grounded walls of the combustor. To assess the electric field effects on the development of gasification/combustion during co-firing of straw with propane, complex measurements of the main gasification/combustion characteristics were carried out by varying the bias voltage of the axially inserted electrode and by limiting the electric current to $7 \mathrm{~mA}$. Kinetic study of the weight loss rate of straw and the composition of volatiles let to conclude that the general trend of the electric field effect on the processes developing during the thermal decomposition/gasification of straw is an enhancement of the formation of combustible volatiles $\left(\mathrm{CO}\right.$ and $\left.\mathrm{H}_{2}\right)$ with an improvement of the combustion conditions in the flame reaction zone. The improvement of the combustion conditions results in an increase of the heat output from the reaction zone was by about $10 \%$ and the heat energy produced per mass of burned straw pellets by about $13 \%$. In addition, the mass fraction of $\mathrm{CO}$ decreases by about $35 \%$ with correlating increase of the $\mathrm{CO}_{2}$ volume fraction in the products. The mechanism of the electric field effects on thermal decomposition of straw and combustion characteristics during co-firing of straw with propane is discussed with account of the thermal and chemical interaction between the components and field-induced ion wind, and the Lorentz force effects on the flame.
\end{abstract}

Keywords: co-firing, straw, pellets, propane, electric control, gasification, combustion.

\section{Introduction}

The current research is in line with the EU-defined energy and environmental objectives: to reduce greenhouse gas (GHG) emissions by $40 \%$ and to increase the energy production from renewable energy sources and energy efficiency by $27 \%$ until 2030 [1]. The woodworking waste nowadays is used to produce high-tech composite materials for the construction industry, as a result the price of wood is growing, and energy producers show their interest in wider use of the relatively problematic plant biomass - agriculture residues (straw), developing different technologies for cofiring of straw with solid fuels [2-4] or gas [5;6]. The results of the previous experimental studies allow to conclude that co-firing of straw with solid fuels (wood, peat, coal) in different proportions can be used to control the combustion characteristics and composition of flue gas [7-9].

An alternative approach for wider use of straw is co-firing of straw with gaseous fuels (natural gas, propane), because co-firing reduces $\mathrm{GHG}$ and polluting $\mathrm{NO}_{\mathrm{x}}$ emissions. Besides, during co-firing of straw with gas, the no solid-phase interaction (as it was found during co-firing of biomass with fossil solid fuel) and the formation of ash only refer to the thermochemical conversion of straw, thus the ash can be used as fertilizer to improve the soil. Providing the preliminary experimental study of the processes developing at co-firing of straw with gas, it has been detected that the main gasification/combustion characteristics are strongly influenced by the thermal and chemical interaction between the components with unpredictable variations of combustion dynamics and composition of emission at different stages of thermochemical conversion of straw. This requires development of an effective control technology capable to provide control of thermal decomposition of straw, mixing of the reactants and combustion of the fuel mixture.

The results of previous studies suggest that development of such technology is possible using the electric field effects on the flame [10]. They include the field-induced ion wind effects [11, 12] and the Lorentz force effects on the flow vorticity and mixing of the reactants [10]. To assess the influence of these effects on development of combustion dynamics co-firing straw with propane, the main aim of the current study is to provide a more detailed complex experimental study of the processes developing, if the electric field is applied to the flame base. 


\section{Experimental studies}

The electric field effects on wheat straw thermochemical conversion during co-firing with gas (propane) were studied experimentally using a batch-size pilot device TRL-4 with the heat output up to $4.5 \mathrm{~kW}$. The device combines a biomass gasifier, water-cooled sections of a combustor and a propane burner with a heat output up to $0.7 \mathrm{~kW}$. The gasifier was filled with straw pellets up to the inlet nozzle of propane flame with total mass of the pellet layer $-430 \mathrm{~g}$. The radially injected propane flame flow initiated and supported the thermal decomposition of straw pellets. The average rate of the wheat straw thermal decomposition was $0.16-0.20 \mathrm{~g} \cdot \mathrm{s}^{-1}$, determining the average overhaul duration of the wheat straw thermochemical conversion $2500-2700 \mathrm{~s}$. The experimental study was carried out at the constant primary and secondary swirling air supply rates $\left(301 \cdot \mathrm{min}^{-1}\right.$ and $401 \cdot \mathrm{min}^{-1}$ respectively), determining the average air excess ratio in the gasifier $\alpha \approx 0.5$ and the near-stoichiometric combustion conditions in the flame reaction zone $(\alpha \approx 1-1.2)$. The electric control of the gasification/combustion characteristics developing downstream of the device was carried out using the axially inserted electrode at the flame base. The bias voltage of the electrode relative to the water-cooled walls of the device was varied from $0.6 \mathrm{kV}$ up to $1.8 \mathrm{kV}$ by limiting the current in a space between the electrodes to $7 \mathrm{~mA}$.

The experimental study of the electric field effect on thermal decomposition of wheat straw pellets co-firing with propane involved complex measurements of the weight loss rate $(\mathrm{dm} / \mathrm{dt})$ and composition of volatiles entering the combustor using the methodology with accuracy of the measurements, which is described in [9]. The electric field effect on the combustion dynamics was estimated providing complex measurements of the flame temperature, flow dynamics, heat output, heat energy produced per mass of the burned pellets and the composition of the products.

\section{Experimental results}

The effect of the electric field on the flame at co-firing of straw with propane closely links to formation of the flame ions. During burnout of hydrocarbon fuel formation of the flame ions $\left(\mathrm{CHO}^{+}\right.$, $\mathrm{H}_{3} \mathrm{O}^{+}, \mathrm{C}_{3} \mathrm{H}_{3}{ }^{+}$) refers to development of the chemo-ionization reactions between the flame species $[11 ; 13]$ :

$$
\begin{gathered}
\mathrm{CH}+\mathrm{O} \rightarrow \mathrm{CHO}^{++} \mathrm{e} \\
\mathrm{CHO}^{++} \mathrm{H}_{2} \mathrm{O} \rightarrow \mathrm{CO}+\mathrm{H}_{3} \mathrm{O}^{+} \\
\mathrm{CH}_{3}{ }^{++} \mathrm{C}_{2} \mathrm{H}_{2} \rightarrow \mathrm{C}_{3} \mathrm{H}_{3}{ }^{++} \mathrm{H}_{2}
\end{gathered}
$$

During co-firing of straw with propane, burnout of propane plays a significant role in formation of $\mathrm{H}_{2} \mathrm{O}\left(\mathrm{C}_{3} \mathrm{H}_{8}+5 \mathrm{O}_{2} \rightarrow 3 \mathrm{CO}_{2}+4 \mathrm{H}_{2} \mathrm{O}\right)$, which is responsible for consumption of the primary ion $\mathrm{CHO}^{+}$, and production of the $\mathrm{H}_{3} \mathrm{O}^{+}$ion (2), which is suggested to be the dominant ion in hydrocarbon flames [13]. For fuel-rich conditions $\mathrm{C}_{3} \mathrm{H}_{3}{ }^{+}$is accepted as the dominant ion [14]. When the electric field is applied to the flame base, the electric body force induces the drift motion of the flame ions in the field direction. The elastic collisions between the accelerated flame ions and the neutral flame species enhance the ion wind formation, which is responsible for development of the field-induced processes of heat and mass transfer [11]. At given pilot device configuration, the field-induced ion drift motion disturbs the flow dynamics and enhances the processes of the reverse axial and the radial heat mass transfer. This is confirmed by the measurements of the flow velocity and the flame temperature profiles with estimation of the field effect on the average values of the flow velocity components and the temperature at different stages of straw thermochemical conversion. The results of the experimental study confirm that the field-induced processes of the reverse axial and radial heat/mass transfer slow down the flow velocity components entering the combustor to the minimum value with a correlating decrease of the flame temperature close to the flame axis $-r / R=0-0.5$; $L / D=3.4$ (Fig. 1-a). In addition, an increase of the temperature along the outside part of the flame reaction zone $-r / R=0.5-1$ (Fig. $1-\mathrm{a}, \mathrm{b}$ ) evidences the radial expansion of the flame reaction zone, which is followed by a correlating increase of the heat output from the device (Fig. $2-a, b$ ). 

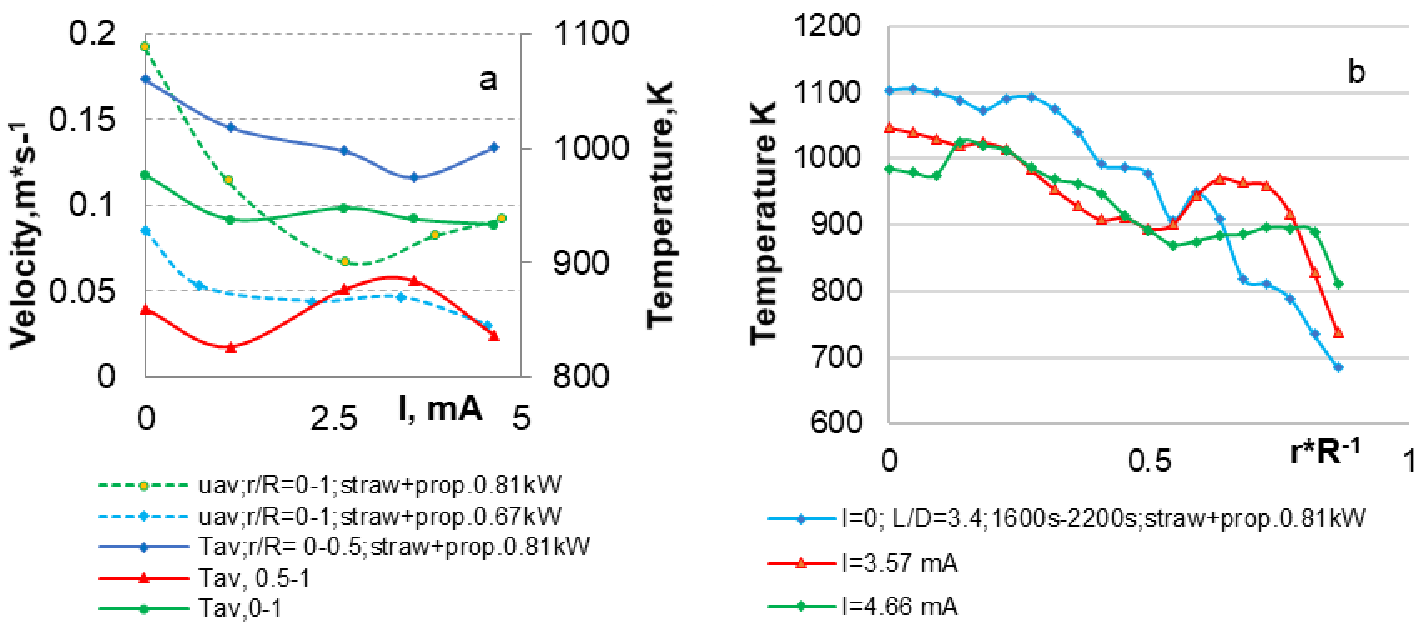

Fig. 1. Electric field effect on average values of axial flow velocity and flame temperature (a); field effect on flame temperature profiles $(b)$

According to Figure 1-a, the field effect on the average values of the flow velocity is increased by raising the additional heat supply provided by the propane flame flow into the device. In accordance with the $\mathrm{CHO}^{+}$ion reaction with water vapour (2), increase of the propane supply into the burner results in enhanced formation of the flame ions, predominately $\mathrm{H}_{3} \mathrm{O}^{+}$. Therefore, increasing the propane supply into the burner significantly affects the field-induced drift motion of $\mathrm{H}_{3} \mathrm{O}^{+}$responsible for the field-enhanced reverse axial and radial heat/mass transfer and local variations of the flow velocity and the flame temperature (Fig. $1-a)$.
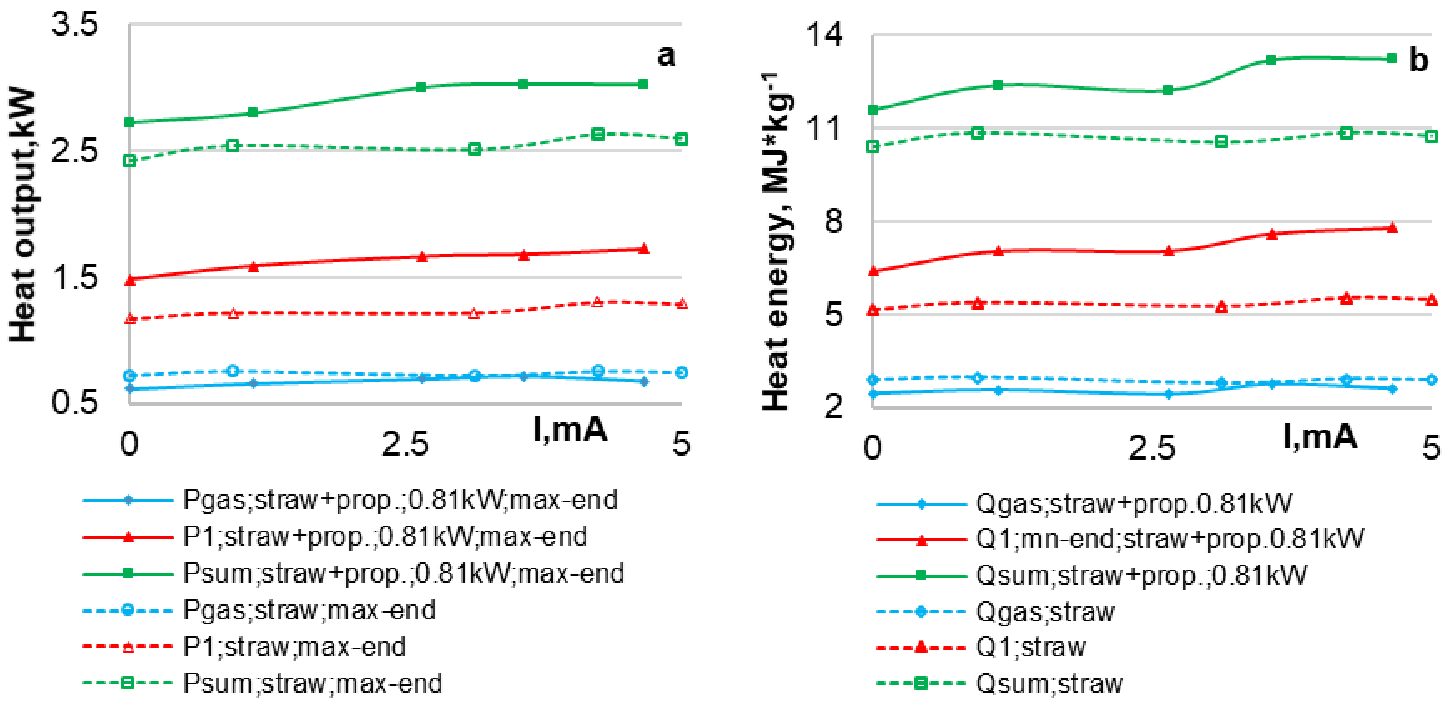

Fig. 2. Electric field effect on heat output from device during fire of straw alone and co-fire with propane (a); field-induced variation of produced heat energy per mass of burned straw and during co-fire of straw with propane (b)

Considering the flame response to the electric field-induced ion drift motion it should be noted that the field-induced variations of the main flame characteristics are interrelated with the changes in the thermal decomposition of straw and the formation of combustible volatiles. If straw decomposes without propane co-fire, the field-enhanced reverse axial heat/mass transfer promotes enhanced heating of straw pellets and thermal decomposition of the main constituents of straw: hemicelluloses, cellulose and lignin. As a result, the weight loss rate of the straw pellets increases from 0.17 up to $0.2 \mathrm{~g} \cdot \mathrm{s}^{-1}$ with correlating field-enhanced increase of the volume fraction of combustible volatiles (CO) (up to the peak value $60-70 \mathrm{~g} \cdot \mathrm{m}^{-3}$ ) entering the combustor and sharp decrease during the transition to the after-flame combustion stage $(t>2000 \mathrm{~s})$. If straw is co-fired with propane, the field-enhanced heat transfer promotes a primary increase of the weight loss rate of straw up to the peak value, which 
corresponds to the ion current about 2.6-3.0 mA, and then tends to decrease, if the ion current continues to grow (Fig. 3 - a). Besides, co-firing straw with propane, field-enhanced and more lasting (up to $2200 \mathrm{~s}$ ) release of combustible volatiles (5) entering the combustor during the after-flame combustion stage is observed (Fig. 3 - a, b). Providing the analysis of the field effect on thermal decomposition of straw, it has been suggested that the electric field enhanced the reverse drift motion of $\mathrm{H}_{3} \mathrm{O}^{+}$from the reaction zone up to the surface of the carbonized straw pellets is associated with recombination of these ions, thus decreasing the ion current (Fig. $3-$ b) and initiating the development of the endothermic water-gas reactions at the surface of biomass char $(4,5)$. The field-induced recombination of $\mathrm{H}_{3} \mathrm{O}^{+}(4)$ and development of the endothermic water gas reaction (5) are responsible for a decrease of the temperature and weight loss rate of straw pellets with more lasting formation of $\mathrm{CO}$ and $\mathrm{H}_{2}$ during the char combustion stage $(t>1500 \mathrm{~s}$ ) (Fig. $3-\mathrm{a}, \mathrm{b}$ ).

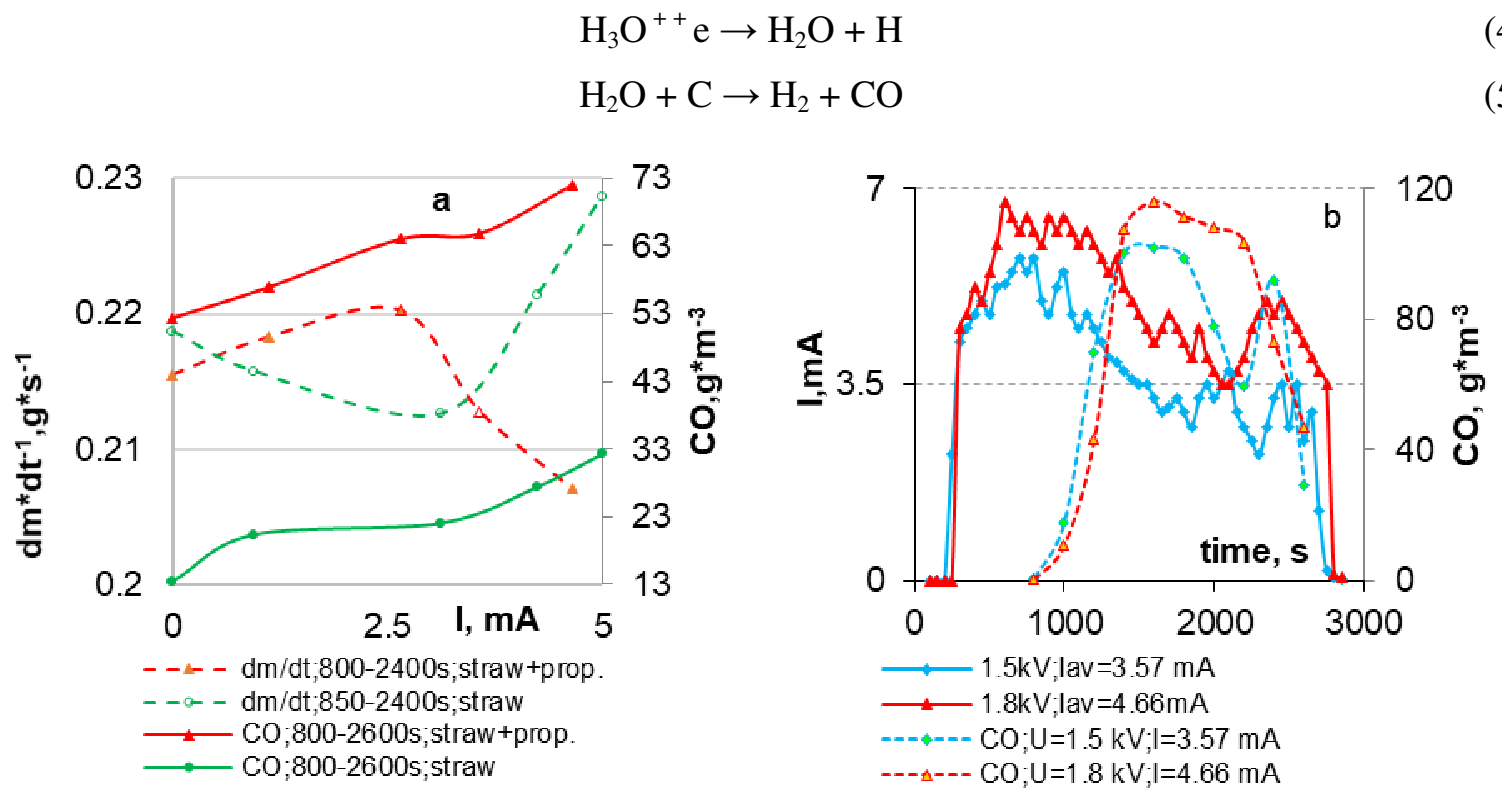

Fig. 3. Electric field-induced variations of weight loss of straw pellets and formation of volatiles at co-firing straw with propane (a); Time-dependent variations of ion current and volume fraction of volatiles entering combustor at co-firing of straw with propane (b)

The competitive processes of the field-enhanced reverse axial heat/mass transfer and development of the field-induced endothermic water-gas reactions close to the surface of the carbonized straw pellets determining the field-enhanced formation of volatiles (Fig. $3-\mathrm{a}, \mathrm{b}$ ) influence the combustion conditions in the flame reaction zone and the heat output from the device. The estimation of the field effect on the combustion conditions confirms that the field-enhanced formation of volatiles entering the combustor correlates with a decrease to the minimum of the average air excess ratio in the flame reaction zone (from $\alpha=1.23$ at $\mathrm{I}=0$ to $\alpha=1.02$ at $I=0.26 \ldots 3.00 \mathrm{~mA}$ ), improving the combustion conditions of volatiles entering the combustor. It should be noted that the minimum value of the air excess ratio in the flame reaction zone corresponds to the maximum value of the weight loss rate of straw pellets and slightly increases up to $\alpha=1.16$ at $I>3 \mathrm{~mA}$. This suggests that the development of the endothermic water gas reactions slightly slows down the processes of thermal decomposition of raw biomass. The field-induced improvement of the combustion conditions is confirmed by an increase of the produced heat energy per mass of burned straw pellets (Fig. $2-$ b) with a correlating decrease to the minimum value of the mass fraction of unburned volatiles in flue gas (Fig. $4-$ a) both during self-sustaining burnout of volatiles (max-end), as well as during the process of straw thermochemical conversion overall (min-end). As follows from Fig. $4-$ a, a slight increase of the mass fraction of unburned volatiles is observed during the after-flame combustion stage, when the field-enhanced endothermic water-gas reactions slightly reduce the burnout of volatiles.

Finally, providing the analysis of the field effect on the processes developing during co-firing of straw with propane, a conclusion has been drawn that field-induced processes of heat mass transfer 
significantly affect formation of the temperature-sensitive $\mathrm{NO}_{\mathrm{x}}($ Fig. $4-$ b). As follows from Fig. $4-$ $\mathrm{b}$, increasing of the bias voltage of the axially inserted electrode and the ion current up to $2.6 \mathrm{~mA}$, the field-enhanced improvement of the combustion conditions, which is defined by the decrease to the minimum value of the air excess in the flame reaction zone, and the enhanced heat produced during the thermal decomposition of straw pellets (Fig. $3-\mathrm{a}$ ), are raising the emission of polluting $\mathrm{NO}_{\mathrm{x}}$. The mass fraction of $\mathrm{NO}_{\mathrm{x}}$ in the products starts to decrease after reaching the peak value, when the fieldenhanced development of the endothermic water-gas reactions results in a decrease of the weight loss rate of straw with correlating increase of the air excess in the flame reaction zone.
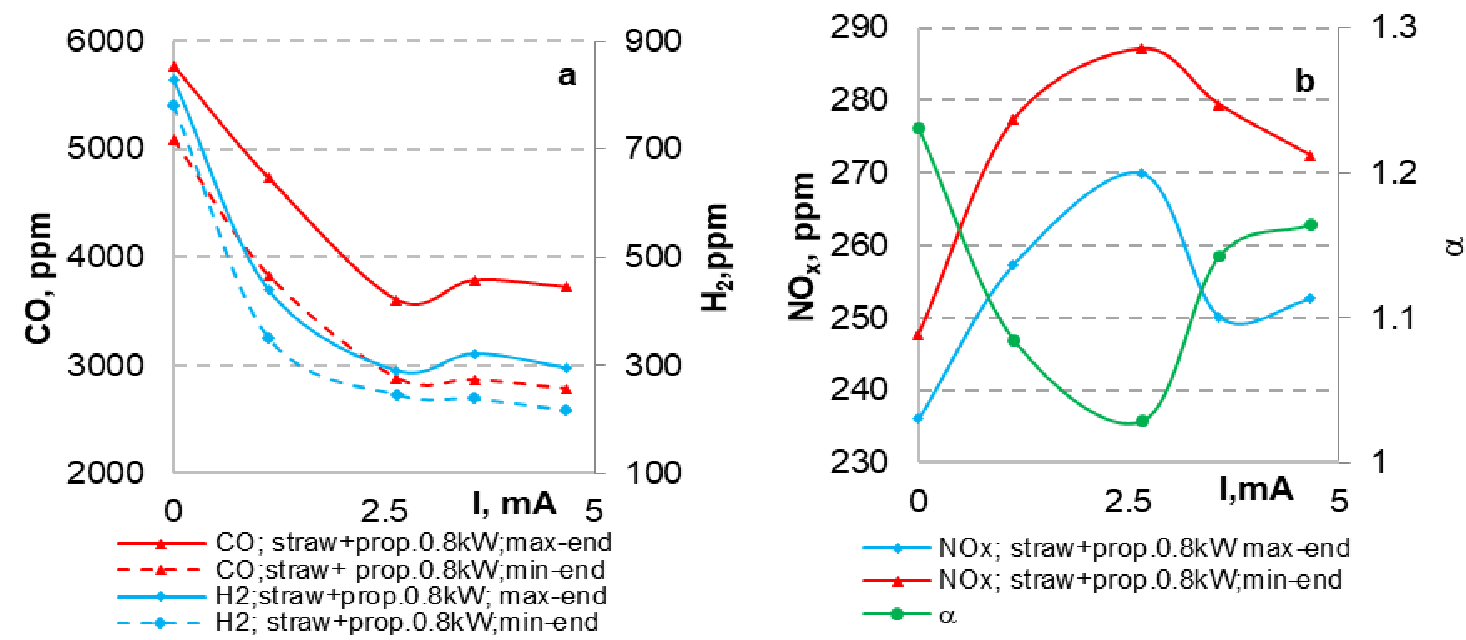

Fig. 4. Electric field effect on products composition at co-firing of straw with propane:

$a$ - field-induced variations of mass fraction of unburned volatiles $\left(\mathrm{CO}, \mathrm{H}_{2}\right) ; b$ - field-induced

variations of air excess ratio in reaction zone and formation of $\mathrm{NO}_{\mathrm{x}}$ during self-sustaining

burnout of volatiles (max-end) and whole process of straw thermochemical conversion

Finally, the results represented above suggest that the electric field effects on the main gasification/combustion characteristics during straw co-firing with propane can be used to provide control of the gasification/combustion characteristics of straw, heat output from the device and the product composition.

\section{Conclusions}

Considering of the results of the experimental studies carried out in this work leads to the conclusions:

1. If the electric field is applied to the flame base, the field-enhanced processes of the reverse axial and radial heat mass transfer are responsible for the variations of the flow dynamics, enhancing the thermal interaction between the flame and straw pellets, decomposition of straw, formation of volatiles and improving the combustion conditions, the main flame characteristics and the product composition.

2. The field-induced ion wind motion up to the surface of the carbonized straw pellets at co-firing straw with propane promotes development of competitive processes of the enhanced thermal and chemical interaction between the flame and straw pellets depending on the bias voltage of the axially inserted electrode and on the ion current in the space between the electrodes. Increasing the ion current above $3 \mathrm{~mA}$, the field effect enhances the development of the endothermic watergas reactions at the surface of straw pellets with improved formation of volatiles by limiting the thermal decomposition of straw, burnout of combustible volatiles and formation of thermosensitive $\mathrm{NO}_{\mathrm{x}}$ emission.

\section{Acknowledgements}

The authors would like to express their gratitude for financial support from the European Regional Funding for Project SAM 1.1.1.1. /16/A/004. 


\section{References}

[1] 2030 climate \& energy framework, Climate Action. [online] [02.01.2019]. Available at: https://ec.europa.eu/clima/policies/strategies/2030_en

[2] Livingston W.R. Advanced biomass co-firing systems, Doosan Babcock, Technology and Engineering, 15 p. [online] [02.01.2019]. Available at: http://citeseerx.ist.psu.edu/viewdoc/ download doi $=10 \cdot 1 \cdot 1.468 .9929 \&$ rep $=$ rep1\&type $=$ pdf

[3] Pedersen L. S., Nielsen H.P., Kill S., Hansen L. A., Dam-Johansen K., Kildsig F., Christensen J., Jespersen P. Full-scale co-firing of straw and coal. Fuel, vol. 75, issue 13, 1996, pp. 1584-1590.

[4] Nordgren D., Hedman H., Padban N., Boström D., Öhman M. Ash transformation in pulverised fuel co-combustion of straw and woody biomass. Impacts of fuel quality on Power Production \& Environment. Lapland, Finland, August 29 - September 3, 2010, pp. 1-12. [online] [02.01.2019]. Available at: https://www.diva-portal.org/smash/get/diva2:987574/FULLTEXT01.pdf

[5] Overgaard A.P., Larsen E., Friborg K., Hille T., Jensen P.A., Kaer S.K. Full-scale tests on cofiring of straw in a natural gas-fired boiler. Proceedings of the 14th European biomass conference and exhibition, Paris, France, October 17-21, 2005, pp. 1-6. [online] [02.01.2019]. Available at: http://citeseerx.ist.psu.edu/viewdoc/download?doi $=10.1 .1 .561 .1803 \&$ rep $=$ rep1\&type $=$ pdf

[6] Agbor E.U. Biomass co-firing with coal and natural gas. Thesis Master of Science, University of Alberts, Department of Mechanical Engineering, Canada 2015, 119 p. DOI: 10.7939/R3DJ58T7F [online] [02.01.2019]. Available at: https://era.library.ualberta.ca/items/8a0929a3-1cdd-4cafb058-c2195f5a4c1e

[7] Barmina I., Kolmickovs A., Valdmanis R., Zake M., Kalis H., Strautins U. Experimental study and mathematical modelling of straw co-firing with peat. Chemical Engineering Transactions, vol. 65, 2018, pp. 91-96. DOI:10.3303/CET1865016 [online] [02.01.2019]. Available at: http://www.aidic.it/cet/18/65/016.pdf

[8] Barmina I., Kolmickovs A., Valdmanis R., Zake M., Kalis H., Strautins U. Kinetic study of the thermal decomposition and co-combustion of straw pellets with coal. Chemical Engineering Transactions, vol. 70, 2018, pp. 247-252. DOI: 10.3303/CET1870042 [online] [02.01.2019]. Available at: http://www.aidic.it/cet/18/70/042.pdf

[9] Barmina I., Valdmanis R., Zake M. The effects of biomass co-gasification and co-firing on the development of combustion dynamics. Energy, vol. 146, 2018, pp. 4-12. DOI: 10.1016/j.energy.2017.04.140

[10] Kalis H., Marinaki M., Strautins U., Zake M. On numerical Simulation of Electromagnetic Field Effects in the Combustion Process, Mathematical Modelling and Analysis, vol. 23, issue 2, 2018, pp. 327-343. 04.2018. DOI: 10.3846/mma.2018.020 [online] [02.01.2019]. Available at: https://journals.vgtu.lt/index.php/MMA/article/view/1434/1143

[11]Lawton, J., Weinberg, F. Electric Aspects of Combustion. Oxford, UK: Clarendon Press, 1969, $650 \mathrm{p}$.

[12] Colannino, J. Electrodynamic Combustion Control Technology. A Clear Sign White Paper, Clear Sign Combustion Corporation, Seattle, 2012. [online] [02.01.2019]. Available at: https://www.clearsign.com/wp-content/uploads/2012/07/ClearSign-Whitepaper-2012-06-18.pdf

[13] Pedersen T.W. Ionic structure of methane flames, $\mathrm{Ph}$. D. thesis, Iowa State University, Retrospective Theses and Dissertations, 1991, 85 p. DOI: 10.31274/rtd-180813-11433 [online] [02.01.2019]. Available at: https://lib.dr.iastate.edu/rtd/10063

[14] Eraslan A.N., Brown R.C. Chemiionization and Ion Molecule Reactions in Fuel-Rich Acetylene Flames, Combustion and Flame, vol. 74, 1988, pp. 19-37. 